\section{SOME CLINICAL OBSERVATIONS WITH NEW REMEDIES. ${ }^{1}$}

BY NESTOR TIRARD, M.D. LOND., F.R.C.P. LOND.,

PROFESSOR OF MEDICIN, KING'S COLLEGE, LONDON ; IIIXSICIAN TO KING'S COLLEGE HOSPITAL, W'C.

WHEN I last had the honour of reading a paper before this society on Some Dangers of Hypnotics certain members were kind enough to express a hope that my next contribution would deal with clinical observations concerning some of the new remedies which had been used in my wards or in my private work. The kindly reception of my last paper has encouraged me to attempt to-day to meet this desire and to place before you some observations which, though perhaps fragmentary and inconclusive, may yet, I hope, prove of interest and at least afford material for discussion and for an interchange of records of experience.

The term "new remedies" I employ to include some preparations which are not to be found in the British Pharmacopœia, some which have been introduced since the issue of the current Pharmacopœia in 1898, some which, for aught I know, may never be admitted or may not appear under their present familiar names if they are protected by patent rights. This is not a question which concerns me greatly, the important point being the investigation of their claim to any consideration. It is impossible to wait for this question to be settled by official authority. Our patients look to us for guidance when perplexed with persistent advertisements and we must be in a position to answer their inquiries without delusive evasions. In dealing with new remedies the rule I have followed, and I believe it is the only safe rule, is not to be led into trying the last new remedy without being in possession of full information of its nature and composition. Details of the method of preparation are not so important, but we must know something about a new drug besides the name and the purposes for which the manufacturer deems it may be of service.

The drugs I propose speaking of to-day are the following: uricedin, urotropin, aspirin, mesotan, and ovoferrin or iron vitellin. You will find that my remarks are not necessarily in praise of any of these preparations; while indicating what I take to be the limits of utility I wish also to point out certain dangers or inconveniences which may arise. I hold no brief on behalf of these drugs but wish to tell a plain unvarnished tale of the results $I$ have had with them and at the same time to give some words of warning against their indiscriminate employment. Fach and all of these may give rise to trouble. They might almost be compared to dynamite or gunpowder; they are useful if properly employed, hazardous if used unskilfully and recklessly. When the possibility of danger is realised there is comparative safety, but if used without due knowledge great risks may be incurred. We frequently hear that every man is "a fool or a physician by the time he is forty." This is a hard saying, since we know that all men of forty are not legally qualified to practise. Perhaps there is a fallacy in the major premiss, but, however that may be, you will soon see that I should not recommend the employment of any of these drugs by the unqualified public.

Uricedin.-The first drug on my list is uricedin. According to Martindale's Extra Pharmacopœia this is a German speciality which occurs in brownish-yellow granules which are soluble in water. It is said to be prepared from concentrated lemon-juice by treating it with sulphuric and hydrochloric acids, neutralising with soda, adding lithium citrate, and evaporating to dryness. It has, according to the same authority, been recommended for gout, gravel, urinary calculi, articular rheumatism, and uric acid diathesis, and the dose is given as from one to two drachms. The statements that have been made respecting this drug are rather conflicting. It has been said that it imparts to the urine the property of dissolving uric acid; that it exercises no injurious effect upon the stomach; that large doses have only been known to cause a slight relaxation of the bowels; and that it converts insoluble uric acid into the more soluble acid urate of sodium. My clinical observations agree generally with these statements but I should be disposed to lay

1 A paper read before the Therapeutical Society on Dec. 20th, 1904. greater stress upon the laxative action. Several of my patients with chronic gout have volunteered the remark that in the moderate doses which I have employed they have found that an easy satisfactory action of the bowels has been produced. One patient, who had suffered long from gout, expressed more gratitude for the pleasant laxative action than for any relief of pain. In acute gout, both in hospital practice and in private work, it has not given me the same degree of satisfaction, nor have I been able to confirm the statements relative to its value in cases of renal calculus. I have tried it in some cases of migraine but the results have not been encouraging. To judge from some of the recent literature which has been circulated to the medical profession I fear that, despite its pleasant laxative action in chronic gout, uricedin is likely to suffer in general estimation on account of exaggerated claims for its employment. It does not inspire confidence to find that it is recommended that its use should be "persevered with for a long timeperhaps even for years."

Urotropin is almost too familiar to need formal introduc. tion but for the sake of consistency it may be well to remind you that it rejoices in the somewhat ponderous chemical name of hexamethylenetetramine and that it is prepared by combining ammonia and formaldehyde. Martindale states that it consists of colourless crystals with an alkaline reaction; it is easily soluble in water, less so in alcohol, and almost insoluble in ether. It is further stated to be a valuable diuretic and solvent of uric acid concretions, to relieve cystitis associated with incontinence of urine, and to destroy typhoid bacilli in the urine. There is, however, one word of warning-viz., that it may cause hæmaturia unless well diluted. The dose is given as from five to 15 grains. On looking into the literature connected with urotropin I have been sorry to find that the list of its misdeeds has been considerably increased. It has been held to be responsible for producing the following symptoms: irritation of the stomach, diarrhœa, abdominal pain, a measles-like rash, renal irritation, albuminuria, strangury, and irritant action on raw surfaces in the urinary passages and hæmoglobinuria. These actions have been said to be due to special susceptibility to formaldehyde, to interference with the usual disposition of formaldehyde in the body, or to the liberation of an unusually large quantity of it. Some two years before these suggestions were made Cammidge maintained that the liberation of formaldehyde did not occur within the body, that the urine of persons taking 30 grains of urotropin a lay did not contain formaldehyde, and he suggested that the antiseptic properties might be due to the formation of new urotropin compounds.

My experience with urotropin in private work has been far greater than in the wards, since many patients for whom the drug might be employed are scarcely sufficiently ill to require ward treatment. At the onset let me say that the long catalogue of ill-effects has not come within my experience; in only one case has there been complaint of slight lumbar pain, and although at the time I did not feel satisfied that it was due to the urotropin it certainly ceased when the drug was discontinued. I am inclined to attribute this freedom from unpleasant symptoms to the fact that $I$ have invariably given instructions that the powder should be taken in at least five ounces of water and have generally employed Contrexéville water for this purpose. The cases in which I have given urotropin have been of varied nature; the general indication has been the presence of pus in the urine, whether resulting from irritation of the renal pelvis by calculi or by crystals of uric acid, or when associated with offensive conditions from the presence of micro-organisms. I would not venture to say that this treatment has sufficed to dissolve uric acid concretions-indeed, in some of my cases subsequent surgical operations were required; but, on the other hand, I would affirm that in every case I have found that the urine speedily lost its offensive character and that there was generally a rapid decrease in the amount of deposit. Further, I can say that those who had hitherto been passing quantities of sand lost this trouble during the treatment; this improvement may, however, have been due to the increased quantity of liquid consumed rather than to a specific action of urotropin. In leaving this drug I would venture to suggest that should undesirable symptoms arise during its adminis. tration it would be well to ascertain whether it has been taken in accordance with instructions before too hastily discarding it in favour of some other line of treatment.

Aspirin.-This drug has been regarded as acetyl salicylic 
acid or salicyl acetic acid. It is a fine white crystalline powder, sparingly soluble in water, and is given in suspension, in cachets or in compressed form. It has been used as a substitute for salicylic acid and the salicylates. My experience with this remedy is comparatively limited and I do not desire to come into conflict with those of more extended experience. Having tried it in several cases of acute rheumatism I have not been convinced that for this purpose it possesses any advantage over salicylic acid or the salicylates and have returned to their employment. In some patients dyspeptic symptoms followed its use in addition to very profuse perspiration ; the former symptoms have sometimes been accompanied by some diarrhœa which has sufficed to produce a strong disinclination to continue the use of this remedy. The cases in which I have found it to be of most service are those of severe headache occurring as the result of overwork or over-anxiety, especially when there are evidences of a gouty diathesis. Under these conditions I have frequently found that a dose of ten grains before going to bed has produced free perspiration, which has been followed by relief of pain and by refreshing sleep. I have also used aspirin for migraine but although it has occasionally been of service it has often failed. From the perspiration it induces I never give aspirin unless the patient is on the point of going to bed.

Mesotan.-This is a yellow liquid, almost odourless, or with a slight aromatic odour. It is the methoxy-methyl ester of salicylic acid. It is insoluble in water, soluble in alcohol, and readily miscible in olive oil. It is readily absorbed by the skin, salicylic acid being found in the urine shortly after its local application. It is stated to have been used with excellent results in all forms of rheumatic and gouty affections. In my hospital work mesotan mixed with one or two parts of olive oil has appeared to afford relief in the after-treatment of acute rheumatism. It has not been of any service during the continuance of the fever, but after the fall of temperature many of my patients have said that they have quickly lost pain and stiffness in their joints with the local application of mesotan. While fully aware of the possible fallacy of such observations I have been struck by their unanimity, which can scarcely be a coincidence. In some cases of gonorrhoal rheumatism mesotan has not given the slightest relief and in one such case well-marked local irritation followed its use. At the time I was inclined to think the patient had been too energetic in his desire to rub in a quantity, but $I$ have since seen it stated that this result has been observed by others, when after the application of mesotan the limb has been surrounded with an impervious covering, while another suggestion is that the irritation is due to admixture with water and decomposition of the mesotan. Both points are noteworthy as they supply hints for directions. Mesotan should be free from water; it should not be used without dilution with olive oil, it should be applied with a brush without friction, and the surface should not be subsequently covered with thick flannel, cotton-wool, or protective tissue.

Ovoferrin or iron vitellin.-Some present may remember that in a paper on the Treatment of Some Forms of Anæmia ${ }^{2}$ I recently gave the results of some observations with this substance. I may, however, state here that this substance is produced by heating together under pressure solutions of serum albumin and iron tartrate ; the resulting precipitate is freed from impurities and supplied in solution with just enough alcohol to check decomposition. The dose of this solution is from two fluid drachms in an ounce of water three times a day. In this paper, after mentioning the general objections to many of the official forms of iron and its compounds and the various efforts to obtain a true organic iron preparation, I gave details of some investigations which had been conducted in my wards with ovoferrin. The general principle was first to estimate the percentage of hæmoglobin in the blood and to make subsequent estimations at intervals of a week during the administration of the new remedy. For the details I would venture to refer you to my paper but the conclusions I would like to summarise here. The hæmoglobin in most cases increased markedly within a short time and synchronously there was great improvement in digestive power and in general well-being. The most satisfactory features were the readiness with which the remedy was taken, owing to its pleasing appearance and its absence of taste, the cheering rapidity of the improvement,

2 The Practitioner, August, 1904. and the total absence of any digestive disturbance or constipation as a consequence.

$\hat{\mathrm{I}}$ am tempted to refer once more to this subject since further experience has not weakened the views then expressed and I am able to say more of one of the cases which did not then afford full satisfaction. In a case of pernicious anæmia we watched a rapid reduction of hæmoglobin with considerable anxiety and finally gave liquor arsenicalis in addition to the ovoferrin. When my paper was written the hæmoglobin had risen from 25 to 30 per cent. and in spite of this small proportion it was noted that the aspect had improved very materially. The hæmoglobin increased from this date (June 20th) until by July 19th it had reached 64 per cent. ; at this time 15 minims of liquor arsenicalis were being given three times a day. This dose produced keratosis of the palms of the hands and some smarting of the eyelids, together with loss of appetite and abdominal pain. The arsenic was accordingly stopped and it is interesting to note that although there was a subsequent slight fall in the percentage of hæmoglobin the general condition remained satisfactory.

And now for the word of warning connected with this preparation. Do not forget that this organic preparation of iron only contains sufficient alcohol to arrest decomposition when undiluted and that it should therefore only be mixed with water at the time when it is taken; neglect of this simple precaution is likely to produce disastrous results.

In conclusion I would like to repeat that I am well aware of the numerous sources of possible fallacy inseparable from any attempt to determine the value of remedies from clinical observations. These risks are necessarily greater when investigating remedies used for the relief of pain. I have endeavoured not to fall into this pitfall and have used guarded terms in such circumstances. On the other hand, there can be few such risks when clinical reports can be supplemented by definite changes like the amount of pus in the urine or the percentage of hæmoglobin in the blood.

Harley-street, W,

\section{HÆMORRHAGIC TYPHOID FEVER.}

By DAVID BLAIR, M.A., M.D. GLASG.,

ASSISTANT MEDICAL OFFICER AT THE COUNTY ASYLUM, LANCASTER.

SEVeral cases and articles bearing on this distinctly rare condition have appeared in the columns of THE LANCET. I refer especially to two contributions by the late Dr. T. J. Maclagan on the Relation of the Bowel Lesion of Typhoid Fever to the General Symptoms of the Disease, ${ }^{1}$ a joint article by Dr. A. G. Nicholls and Mr. G. Everett Learmouth of McGill University on the Hæmorrhagic Diathesis in Typhoid Fever and its Relation to Purpuric Conditions in General ${ }^{2}$ and the description of a case at St. George's Hospital, under the care of Dr. W. Ewart. ${ }^{3}$ In connexion with these the following case and suggestions may be of some interest.

A woman, aged 24 years, was admitted to the asylum on July 12th, 1895. She had earned her living as a charwoman. Since the age of 14 years she had been subject to epileptic fits and had two or three per diem. She was somewhat addicted to drink. When admitted she complained of having suffered from various mysterious maladies and said that she had had a tumour in the side for which she had undergone an operation. She was violent, excited, and had delusions of persecution. Physically she was well nourished but very anæmic. During the whole of her year's sojourn at the asylum she was hypochondriacal, fretful, quarrelsome, and hard to manage. She complained of a pain in her left side, of which there was no physical sign, and insisted on wearing a plaster and bandage over it. Now and again, especially when one happened to be looking, she would gasp, catch her breath and throat and appear to be troubled with something of the nature of globus hystericus. Despite her many drawbacks she was a useful worker in the wards.

On July 2nd, 1896, her bodily health was reported to the

1 The LaNCET, Dec. 8th, 1900, p. 1639, and Jan. 12th, 1901, p. 93. 2 THE LANCET, Feb. 2nd, 1901, p. 305. 3 THE LANCET, July 6th, 1901, p. 25. 